\title{
Trastorno por déficit de atención con hiperactividad y el mejoramiento cognitivo ¿Cuál es la responsabilidad del médico?
}

Marcelo Gorga

\section{Resumen}

El artículo trata del mejoramiento neurofarmacológico de la cognición, uno de los temas más frecuentes en Neuroética y Bioética aplicada a la Neurociencia. Discute acerca del uso racional de estos fármacos. La normalización social, según Georges Canguilhem, unifica la diversidad estableciendo valores en común para una sociedad. El mejoramiento cognitivo farmacológico puede favorecer el cumplimiento de deberes y expectativas sociales surgidos a partir de estos valores. El mejoramiento cognitivo farmacológico cosmético y terapéutico (por ejemplo, el utilizado en el TDAH, caso sobre el que se centra este artículo) implica por parte del médico asumir la responsabilidad de facilitar el cumplimiento de ciertas expectativas sociales, adhiriéndose implícitamente a ellas. En la conclusión se considera necesaria entonces, una reflexión del médico acerca del sentido de estas expectativas teniendo en cuenta valores como la vida, la identidad, la integridad, la libertad, la salud y el bienestar de las personas y comunidades.

Palabras-clave: Cognición. Bioética. Neurociencia. Responsabilidad social.

\section{Resumo}

Transtorno por déficit de atenção com hiperatividade e o melhoramento cognitivo. Qual é a responsabilidade do médico?

$\mathrm{O}$ artigo trata do melhoramento neurofarmacológico da cognição, um dos temas mais frequentados na Neuroética e Bioética aplicada à Neurociência. Discute-se o uso racional destes fármacos. A normalização social, de acordo com Georges Canguilhem, unifica a diversidade estabelecendo valores em comum para a sociedade. O melhoramento cognitivo farmacológico pode favorecer o cumprimento de deveres e expectativas sociais surgidos a partir destes valores. O melhoramento cognitivo farmacológico cosmético e terapêutico (por exemplo, utilizado em TDAH, caso em que este artigo focaliza) implica, por parte do médico, assumir a responsabilidade social de facilitar o cumprimento de certas expectativas sociais, aderindo implicitamente a elas. Conclui-se considerando que é necessária, então, a reflexão do médico sobre o sentido destas expectativas, tendo em vista valores como vida, identidade, integridade, liberdade, saúde e bem-estar de pessoas e comunidades.

Palavras-chave: Cognição. Bioética. Neurociência. Responsabilidade social.

\begin{abstract}
Attention deficit/hyperactivity disorder and cognitive enhancement. Which is the medical responsibility? The article is about neuropharmacological enhancement of cognition, one of the most common topics of the Neuroethics and Bioethics applied to Neuroscience. It discusses the rational use of these drugs. Social normalization, according to Georges Canguilhem, unifies diversity establishing common values for society. The pharmacological cognitive enhancement can help the compliance of the duties and expectations arising from these values. The cosmetic and therapeutic pharmacological cognitive enhancement (for example, used in ADHD, case in which this article is focusing) implies for the physicians the social responsibility of making easier the compliance of certain social expectations, adhering to them implicitly. Then it is necessary for the physician to reflect about the meaning of those social expectations taking into account values such as life, identity, integrity, freedom, health and welfare of persons and communities.

Key words: Cognition. Bioethics. Neuroscience. Social responsability.
\end{abstract}

Graduado marcelogorga@yahoo.com - Centro de Investigações Psicopedagógicas Aplicadas/Escola de Humanidades/Universidade Nacional de General San Martín (UNSAM), Ciudad Autónoma de Buenos Aires/CF, Argentina.

Correspondência

Madero 820, Planta Baja, Departamento 1 CP: 1408. Ciudad Autónoma de Buenos Aires/CF, Argentina.

Declara não haver conflito de interesse. 
Uno de los temas más frecuentes en Neuroética y Bioética aplicada a la Neurociencia es el del mejoramiento cognitivo a través del uso de neurofármacos. Las Ilamadas pildoras inteligentes son neurofármacos que incrementan la habilidad cognitiva de cualquier persona que las tome, tanto en el caso de que si el que lo hace tenga una enfermedad como también si se trate de un individuo sano, en cuyo caso hablamos de un efecto cosmético y de una neurología cosmética.

El uso racional de estos fármacos, de consumo cada vez más difundido, obliga en primer lugar entonces, a retomar la discusión acerca de qué entendemos por normal y patológico. Según el filósofo y médico francés, George Canguilhem ${ }^{1}$, las anomalías, en tanto expresiones de variaciones individuales sobre aspectos específicos, devienen patológicas sólo en relación a un tipo determinado de vida, en el cual ciertos deberes del ser viviente se establecen como ineludibles. Podemos agregar, siguiendo el pensamiento de este autor, que la cultura tiene por efecto alterar el medio de vida de los hombres, lo que hará invariablemente alterar sus deberes y expectativas. Se sigue de esto último que el problema de lo patológico en el ser humano no puede quedar exclusivamente definido a partir de lo biológico.

Frente a la singularidad biológica y cultural del ser humano, la normalización social, en tanto elección y decisión sociales exteriores a ese organismo, se presenta como fenómeno socialmente arbitrario, que unifica la diversidad y establece valores en común para una sociedad. Canguilhem señala que, si existen normas biológicas, es porque la vida al no ser sumisión al medio ambiente sino institución de su propio medio ambiente, por ello mismo pone valores no sólo en el medio ambiente sino también en el organismo. El hombre sano es entonces aquel que puede admitir el avance a nuevas normas. El hombre es sano en la medida en que es normativo con respecto a las fluctuaciones de su medio ambiente ${ }^{2}$. Canguilhem denominará a esta puesta de valores normatividad biológica. Por lo tanto mientras que la demanda de normas es algo interno del organismo biológico, la normalización social descansará sobre una elección y una decisión exteriores a ese organis$m o$, en tanto objeto normalizado ${ }^{3}$.

Sostenemos que el mejoramiento cognitivo farmacológico, tanto en el caso de personas sanas como en el de aquellas que padecen un estado patológico, puede favorecer el cumplimiento de deberes y expectativas surgidos a partir de estos valores en común. El objetivo central de nuestro trabajo es presentar la pregunta y orientar la formulación de respuestas acerca de qué responsabilidad le cabe al médico al momento de indicar un fármaco mejorador cognitivo, tanto para su uso terapéutico (cada vez más frecuente, como en el caso de las personas con Trastorno por Déficit de Atención con Hiperactividad -TDAH-) como en el eventual caso de que se aprobara su uso en personas sanas. Como medio para pensar en las posibles respuestas a la pregunta que nos hemos formulado hemos centralizado nuestro análisis en el uso de los mejoradores cognitivos en las personas con TDAH, tomando en consideración la complejidad del ser humano en tanto ser social y biológico.

\section{¿Qué es la Neuroética?}

Tratándose la Neuroética de un nuevo campo del conocimiento, consideramos necesario hacer referencia a algunas de las definiciones que actualmente tenemos acerca de la misma. A partir del año 2002, distintos problemas asociados a la Neurociencia comenzaron a identificarse como formando parte de un nuevo campo de estudio al que se le empezó a denominar Neuroética. En ese mismo año, la Fundación DANA, un grupo de interés público en los Estados Unidos abocado a la difusión de la nueva ciencia del cerebro, patrocinó un simposio titulado, Neuroética: mapa del nuevo campo. De este mismo simposio surgió la definición de Neuroética dada por Steven Marcus, quien la describió como el estudio de las implicaciones éticas, legales y sociales que se presentan cuando los hallazgos científicos acerca del cerebro y la conducta son llevados a la práctica médica, a las interpretaciones legales y a las políticas en salud y sociales ${ }^{4}$.

La filósofa y neuroeticista sueca Kathinka Evers menciona en su libro Neuroética, que ésta se interesa en los beneficios y los peligros potenciales de las investigaciones actuales sobre el cerebro, interrogándose acerca de temas que durante siglos han sido patrimonio exclusivo de la Filosofía y que hoy parecieran ser objeto de estudio compartido con la Neurociencia como es el caso de la conciencia, el sentido de sí, los valores y la libertad. Evers menciona que podemos dividir la Neuroética en dos grandes ramas: la Neuroética aplicada y la fundamental.

La primera, la Neuroética aplicada, se centra en cuestiones prácticas como son aquellas que advienen de los problemas éticos que surgen por ejemplo a partir del uso de las técnicas de neuroimágenes (resonancias magnéticas nucleares de cerebro, por ejemplo) y el uso de los fármacos y las 
distintas tecnologías que pueden producir mejoramiento cognitivo (como veremos a continuación) y del estado de ánimo. En el caso de la Neuroética fundamental, ésta es la que se interroga acerca de la manera en que el conocimiento de la arquitectura funcional del cerebro y de su evolución puede profundizar nuestra comprensión de la identidad personal, de la conciencia, de la intencionalidad y del desarrollo del juicio moral, entre otros tópicos ${ }^{5}$.

Los neuroeticistas canadienses Erik Racine y Judy Illes, resaltan la relación entre Neuroética y Bioética. Para ellos la Neuroética es un nuevo campo en la intersección entre Bioética y Neurociencia que se centra en la ética de la investigación en Neurociencia y en las consecuencias éticas que surgen de la transferencia de los conocimientos surgidos a partir de la investigación en Neurociencia a la clínica y al dominio público. Con respecto a la clínica, brindaría la oportunidad de una integración de la Ética de distintas especialidades médicas (Neurología, Psiquiatría y Neurocirugía) y de la Ética de la investigación relacionada con la mejora del cuidado de los pacientes ${ }^{6}$.

Para Walter Glannon, filósofo y neuroeticista también canadiense, la capacidad que han demostrado las tecnologías resultantes de los actuales avances en el conocimiento neurocientífico de mapear, intervenir y alterar los correlatos neurales de la mente implican importantes conflictos éticos. Esto es así porque estas técnicas que tienen como blanco al cerebro, pueden revelar y modificar el origen de la mente afectando la identidad personal, el albedrío y otros aspectos de nosotros mismos ${ }^{7}$. Veremos a continuación de qué manera el tema de los mejoradores cognitivos se constituye en un tópico central de discusión para la Neuroética.

\section{¿Qué forma adquiere la normalización social en el caso del TDAH?}

El TDAH ha sido definido por la Academia Americana de Pediatría (AAP), de los Estados Unidos, como el desorden neuroconductual más frecuente en la infancia ${ }^{8}$. El Primer Consenso Latinoamericano sobre TDAH del año 2007, lo ha definido como el trastorno neuropsiquiátrico más común a nivel mundial en la población pediátrica ${ }^{9}$. Dwivedi ${ }^{10}$ menciona la existencia de prevalencias distintas de niños con diagnóstico de TDAH en distintos países del mundo. Las cifras mencionadas por este autor van de un 4,5\% a un 16,6\%. La última guía de diagnóstico y tratamiento del TDAH de la AAP, habla de un porcentaje aproximado de $8 \%$ de niños y jóvenes con TDAH ${ }^{8}$. La pregunta que se formula Dwivedi, y que nosotros compartimos, es si la diferencia en la prevalencia no guarda relación con la falta de definición clara en cuanto a qué es el TDAH.

El diagnóstico del TDAH requiere, según la estadounidense AAP, que la conducta del niño reúna los criterios del Manual Diagnóstico y Estadístico de Desórdenes Mentales (DSM IV), de la también estadounidense Asociación Americana de Psiquiatría (AAP) ${ }^{8,11}$. A su vez, el DSM IV, hace mención a los llamados signos cardinales del TDAH que incluyen conductas compatibles con inatención, hiperactividad e impulsividad. Según la guía de diagnóstico y tratamiento del TDAH de la AAP del año 2011, los criterios del DSM IV continúan siendo los mejor sustentados por las evidencias y los consensos, además representa el mejor método para la comunicación entre clínicos ${ }^{12}$. Según el Primer Consenso Latinoamericano de Trastorno por Déficit de Atención e Hiperactividad del año 2007: El constructo del TDAH no depende de factores culturales ${ }^{13}$. Considérese constructo un término, o grupo de términos teóricos, usados en la formulación de una hipótesis científica con el fin de explicar y predecir hechos ${ }^{14}$.

Por un lado en este consenso se declara una independencia del constructo del TDAH de factores culturales y al mismo tiempo se reconoce la ausencia, al menos actual, de marcadores biológicos específicos que se puedan y se deban buscar y utilizar en la práctica médica habitual, en tal sentido se menciona que el diagnóstico es clínico, los marcadores biológicos como electroencefalograma (EEG), estudios de neuroimagen o pruebas neuropsicológicas no son definitivos o necesarios ${ }^{13}$. La guía de diagnóstico y tratamiento del TDAH de la AAP menciona además que la falla en el funcionamiento es el indicador de la gravedad en el TDAH ${ }^{12}$. Aquí hay que aclarar que la Asociación Americana de Pediatría considera como manifestación de funcionamiento a las relaciones con pares, rendimiento académico, habilidades adaptativas y al funcionamiento escolar ${ }^{8}$.

Estos parámetros tornan necesario recurrir a la referencia de observadores de la conducta de los niños. Según aquel Consenso en la práctica cotidiana de los médicos que diagnostican y tratan a los pacientes con TDAH, se incluye la utilización de entrevistas y escalas de detección y gravedad en las cuales tanto los pacientes, padres y maestros proporcionan información acerca de las conductas observadas en el paciente ${ }^{15}$. Obviamente estas características conductuales (detectadas a través de escalas basadas en los criterios del DSM IV) corren 
el riesgo, por un sesgo de tipo cultural (aparentemente no reconocido por este consenso), de ser interpretadas de formas distintas, por los diferentes observadores (elemento éste tomado en consideración por la guía de la AAP del 2011) lo cual pondría al menos en situación de debate la supuesta objetividad diagnóstica del TDAH alcanzada a través del uso de escalas.

Si volvemos al pensamiento de Canguilhem, éste mencionaba que la normalización social unifica la diversidad y establece valores en común para una sociedad. Con respecto a esta unificación de la diversidad podemos mencionar que un problema que debe ser tomado en cuenta en el caso del DSM IV es que no proporciona mecanismos para determinar la gravedad de un síntoma o conjunto de síntomas (o signos) relacionados con niños según la edad de desarrollo ${ }^{8}$, el sexo o la fuente de información ${ }^{16}$.

La validez de un instrumento o procedimiento de medición se refiere a qué tan bien el mismo mide lo que se propone medir. En líneas generales el tema de la validez genera muchas dudas sobre las características específicas de medición en medicina, por ejemplo, qué tan precisa es la escala de estado funcional para determinada patología o qué tan bien mide determinada característica un cuestionario ${ }^{17}$. En el caso del DSM IV entonces deberíamos considerar que la validez del mismo como instrumento para detectar el punto a partir del cual el deterioro en la atención y el nivel de actividad se convierten en un trastorno, es al menos cuestionable o ameritaría por lo menos algún tipo de salvedad a ser tomada en cuenta por los mismos médicos y demás profesionales de la salud.

Según menciona Boyce ${ }^{18}$, una crítica generalizada al DSM IV ha sido que en un esfuerzo por mejorar la fiabilidad del instrumento a través de una nomenclatura en común que permitiera diagnósticos estandarizados, se sacrificó su validez, considerando que la fiabilidad hace referencia a qué tan reproducibles son los resultados de una medición si la misma se realiza varias veces en el mismo sujeto ${ }^{17}$. Si consideramos a los trastornos mentales como un producto de la interacción dinámica entre la biología cerebral y el contexto socio cultural en el cual un niño se desarrolla, es necesario destacar que el DSM IV no aporta al clínico una herramienta para investigar el comportamiento del individuo en distintos contextos a pesar de señalarse en su Eje IV la necesidad de registrar los problemas psicosociales y ambientales que puedan afectar el diagnóstico, el tratamiento y/o el pronóstico de los trastornos mentales.
Recordemos incluso que el DSM IV propone un sistema multiaxial que implica una evaluación en varios ejes, cada uno de los cuales está en relación con un área distinta de información. A través de la identificación de estas dificultades que el DSM IV presenta como manual de diagnóstico. No pretendemos aquí menoscabar el objetivo y la importancia que el mismo ha tenido y tiene como instrumento que pone énfasis en la necesidad de explicitar definiciones como medio para realizar diagnósticos clínicos fiables. Lo que nos hemos propuesto recalcar con los puntos señalados es que los límites que el DSM IV tiene como herramienta diagnóstica ponen en evidencia la existencia de problemas epistemológicos y potenciales conflictos bioéticos que pueden surgir a punto de partida del uso exclusivo de los criterios de este manual para realizar el diagnóstico de TDAH.

Valores y hechos mensurables definen lo normal

Canguilhem ${ }^{19}$ menciona en su obra Lo normal y lo patológico que el vocabulario técnico y crítico de la filosofía de Lalande designa a la "norma" como la escuadra, es decir aquello que no se inclina ni hacia la derecha ni hacia la izquierda; lo que se mantiene en un justo medio. A su vez, aclara que el Dictionnaire de médecine de Littré y Robin define a lo "normal" como aquello que es conforme a la regla, como aquello que es regular. Por lo tanto normal será aquello que es tal como debe ser y aquello que se vuelve a encontrar en la mayoría de los casos de una especie determinada o aquello que constituye un promedio de un carácter mensurable.

Aquí Canguilhem descubre una ambivalencia en la definición de lo normal pues, en el último caso, describe un hecho y en el primero un valor que el hablante otorga al hecho. Una confusión análoga se presenta en la Medicina, donde el estado normal designa al mismo tiempo el estado habitual de los órganos y su estado ideal. En Medicina, el objeto ordinario de la terapéutica será el restablecimiento de ese estado habitual. En virtud de esto, podemos decir que la atención (y también la actividad, aunque con mayores dificultades operativas en cuanto a la definición de la variable estadística a cuantificar) podría ser evaluada en términos estadísticos en relación a una distribución poblacional pero también en relación a lo que el observador valora como aquello que debe ser.

Frente a esta definición nos preguntamos, ¿̇de qué dependerá que consideremos que un tipo de 
rendimiento atencional sea el que deba ser, y a su vez, sea el que deba ser para cumplir con qué objetivo o expectativa? ¿Podrán esos objetivos o expectativas ser moralmente cuestionables o al menos ameritar una reflexión acerca de su contenido moral? Seguramente sí. Esta respuesta afirmativa nos lleva obligatoriamente a preguntarnos acerca de la existencia de la posibilidad de que esta reflexión se dé en el contexto de las prácticas médicas habituales y de las prácticas en salud en general.

Tantola inatención comola hiperactividad pueden constituir un estado patológico si, utilizando palabras de Canguilhem ${ }^{19,20}$ se asocian a un pathos, es decir un sentimiento directo de sufrimiento, de impotencia y de vida contrariada experimentados por la propia persona. No se estará enfermo entonces únicamente en relación con los otros sino también en relación con uno mismo. En relación al proceso diagnóstico propio de la práctica clínica habitual, ¿en qué orden de importancia está ubicada la experiencia de la enfermedad vivida por el propio niño con TDAH? ¿Se toma en cuenta dicha experiencia?

\section{La interacción entre cerebro y contexto}

La atención y la actividad, como ya mencionamos, se ponen de manifiesto a través de la presencia de determinadas conductas observables. Si partimos del supuesto de que las conductas de las personas son una manifestación particular del funcionamiento del sistema nervioso, pensamos que es posible que haya individuos que puedan presentar alteraciones patológicas en su atención y su nivel de actividad así como podrían presentarlas a nivel de cualquier otra función biológica. Esto no descarta la influencia que el contexto social tiene sobre el funcionamiento biológico del cerebro y sobre la manifestación final de determinadas conductas. Las conductas definidas como disatencionales e hiperactivas son un hecho mensurable de origen biológico influido por el medioambiente.

Thapar ${ }^{21}$ menciona que determinados factores de riesgo genéticos y medioambientales interactuarían en el incremento de la susceptibilidad al TDAH. Se han detectado variantes de genes que darían susceptibilidad a la aparición de rasgos conductuales compatibles con el TDAH. Se han descrito ejemplos de esta susceptibilidad en relación a variantes de los genes para el receptor D4 y D5 de la dopamina, del gen SNAP-25 y a una variante del gen para el transportador de dopamina. Otras variantes de genes se han relacionado con la influencia en el curso de este trastorno. Por ejemplo, una variante del gen para el receptor D4 de la dopamina se ha relacionado con la persistencia en el tiempo de los signos clínicos compatibles con TDAH. A su vez, la presencia de una variante funcional del gen codificante para la enzima COMT y una variante del gen para la enzima MAO A, se han relacionado con la aparición de una conducta antisocial en individuos con TDAH.

La Epigenética es un campo emergente que comprende aquellos cambios hereditarios no mendelianos en la expresión de los genes que no son mediados por alteraciones en el apareamiento de bases de la secuencia de ADN. Implica el estudio de las interacciones causales entre los genes y sus productos. La regulación epigenética media la adaptación al medio ambiente, particularmente bajo condiciones medio ambientales desfavorables, a través de la plasticidad genómica que se traduce en el fenotipo actual ${ }^{22}$. Actualmente estamos frente a la presencia de un esfuerzo científico en aumento por desarrollar modelos estadísticos que puedan ajustarse a estos efectos complejos ${ }^{23}$.

En el caso del TDAH, Thapar menciona también factores epigenéticos intervinientes puestos de manifiesto a través de la interacción gen/medioambiente. Un ejemplo de esta interacción mencionada por el autor es la que muestra la asociación más fuerte que se da entre un haplotipo del DAT1 (combinación de alelos de riesgo en gen asociado al transportador de dopamina) y conductas propias del TDAH, en aquellos individuos con antecedentes maternos de alcoholismo durante el embarazo ${ }^{21}$. En otro estudio ${ }^{24}$ vinculado con la presencia de determinados haplotipos del DAT 1 en adolescentes se ha visto que la presencia de los mismos, sumado a la exposición a contextos familiares que los autores definieron como altamente adversos (evaluados a través del Rutter family adverse index), se ha asociado a la manifestación de niveles más graves de disatención, hiperactividad e impulsividad en comparación con otros tipos de contextos menos adversos y en comparación con grupos de adolescentes con otro tipo de genotipo/haplotipo.

En este trabajo en particular, se consideró como contexto familiar altamente adverso a la presencia de un conjunto de variables sociales entre las cuales se ha mencionado al bajo nivel educativo de los padres, hacinamiento, trastornos psiquiátricos en padres, historia de rupturas familiares o delincuencia, paternidad temprana, presencia de uno sólo de los padres, embarazo no deseado, pobre integración social, pobres habilidades de crianza. 
Obviamente que lo único que podemos concluir con respecto a estas variables sociales es la presencia, según evidencia este trabajo, de algún tipo de asociación estadística entre las mismas, la presencia de determinadas alteraciones genéticas y la presencia de determinadas conductas compatibles con el TDAH, que pondría de manifiesto la necesidad de una profundización en la investigación en cuanto a la potencial causalidad de cada una de estas variables o grupo de variables en relación a las conductas compatibles con el TDAH.

Estos estudios son de gran importancia para mostrar la potencial asociación que se daría entre la presencia de determinadas características biológicas innatas, determinados contextos y determinado tipo de conductas, en este caso, aquellas correspondientes al TDAH. A modo de síntesis entonces, la biología determinaría la mayor susceptibilidad a presentar conductas compatibles con el TDAH y el contexto colaboraría en la manifestación final de las mismas. Este tipo de investigación se sustenta en parte en la idea que una taxonomía objetiva basada en el descubrimiento de marcadores biológicos permitirá la implementación de tratamientos más efectivos. Sin embargo, curiosamente, gran parte de las investigaciones en relación al TDAH parten del supuesto que las categorías diagnósticas detalladas en el DSM IV son válidas lo cual, por lo que hemos mencionado previamente, es al menos para algunos autores cuestionable ${ }^{18}$.

\section{El uso de los mejoradores cognitivos}

Los psicoestimulantes mejoran el rendimiento en memoria de trabajo, una función cognitiva alterada en las personas con conductas compatibles con TDAH ${ }^{25}$. Es el caso específico del psicoestimulante metilfenidato en su uso terapéutico en personas con diagnóstico de TDAH y en personas sanas en la neurología cosmética ${ }^{26,27}$. Para estas últimas, Smith y Farah mencionan en trabajo reciente, que la dextro-anfetamina y el metilfenidato (ambos psicoestimulantes) parecen mejorar la retención de información recientemente aprendida, la memoria de trabajo y el control cognitivo en algunos individuos, sin embargo habría una gran incertidumbre respecto a la dimensión de estos efectos y su dependencia de la dosis, diferencias individuales y especificidad de la tarea ${ }^{28}$.

La posibilidad de este uso ambivalente de los estimulantes (como cosmético y como tratamiento), sumado a las dificultades diagnósticas antes mencio- nadas, hacen pertinentes las preguntas: ¿En quién utilizarlos y por qué?; ¿Quiénes y cómo deberían decidir su uso?; ¿Qué valores estarían en juego?

Si el diagnóstico de TDAH fuera en parte producto de la ausencia de aceptación por parte de miembros del sistema educativo, médicos y familiares de una diversidad de perfiles cognitivos y conductuales mayor a la que actualmente sus comunidades de pertenencia están dispuestas a tolerar, entonces estaríamos frente a la posibilidad de un sobrediagnóstico de esta entidad y al mismo tiempo frente al uso de los psicoestimulantes, ya no como tratamientos de un déficit sino como mejoradores de rendimientos cognitivos no necesariamente patológicos.

\section{Las expectativas de padres y maestros}

Además de farmacológicos, actualmente contamos con abordajes psicoeducativos para los niños con conductas compatibles con el TDAH. Jensen menciona que la medicación psicoestimulante es a menudo efectiva en el corto plazo en la modificación de los llamados signos cardinales del TDAH (inatención, hiperactividad, impulsividad), pero no siempre es efectiva a largo plazo en el mejoramiento funcional del niño (por ejemplo, rendimiento escolar o relación del niño con sus pares y/o adultos). Por otra parte, los abordajes psicoeducativos solos o en combinación con bajas dosis de medicación pueden ser efectivos en el largo plazo en reducir los signos cardinales y mejorar muchos aspectos funcionales ${ }^{29}$.

El Hastings Center ha realizado una serie de workshops con participantes del área clínica, de investigación y académica con el objetivo de analizar las controversias surgidas a partir del uso de tratamientos farmacológicos en niños con trastornos conductuales y emocionales, haciendo particular hincapié en el caso del TDAH. Erik Parens menciona en una publicación sobre las conclusiones surgidas de estos encuentros, que las familias tienen diferentes estilos de crianza y diferentes expectativas con respecto a los niños. En tal sentido el tratamiento farmacológico enfatizaría el valor de la eficiencia, en tanto que las intervenciones psicoeducativas (también se las ha llamado psicosociales en los distintos consensos) enfatizarían el valor del compromiso del niño con padres, pares, maestros o terapistas y de estos con el niño, ya que se interpretaría que el problema no estaría sólo en el cuerpo del niño sino fundamentalmente en la interacción con el contexto ${ }^{30}$. 
A modo de breve reseña histórica en el ámbito latinoamericano, podemos mencionar que el desarrollo de algoritmos de tratamiento para escolares con TDAH en Latinoamérica se inició con el primer consenso de la región celebrado en 2007 en la ciudad de México; este algoritmo tomó en consideración únicamente las opciones farmacológicas. Después del segundo consenso de la región celebrado en 2008, en la ciudad Argentina de Mendoza, quedó clara la necesidad de incluir las intervenciones psicosociales, definiendo de esta manera un algoritmo que permitiera ofrecer un tratamiento multimodal ${ }^{31}$.

El Algoritmo de Tratamiento Multimodal para Escolares Latinoamericanos con TDAH surgido después de los debates dados en el $1^{\circ}$ y $2^{\circ}$ consenso latinoamericano sobre TDAH, menciona en el apartado referido a Evaluación y Diagnóstico que, para una evaluación objetiva de la gravedad sintomática, se recomienda usar escalas validadas para el TDAH en escolares, como el SNAP-IV ${ }^{32}$ o el Cuestionario Latinoamericano. Una vez establecido el diagnóstico, se elabora un plan de intervención con los padres y el paciente. Un plan así debe tomar en consideración las expectativas, creencias, posibilidades económicas y deseos de la familia, así como las opciones terapéuticas y farmacológicas disponibles en cada uno de los países latinoamericanos ${ }^{33}$.

Sostenemos que tomar en consideración las expectativas, creencias y deseos de la familia no sólo debería formar parte de la etapa de definición de la estrategia terapéutica, sino que debería comenzar previamente en la etapa diagnóstica, si nos guiamos por las ideas sostenidas por Canguilhem en cuanto a la participación de los valores en la definición de lo normal. La Declaración de Cartagena ( $3^{\circ}$ Consenso sobre TDAH) del año 2009, expresa ésto cuando afirma que el padecimiento del TDAH es de origen biológico con participación en su expresión de elementos psicosociales ${ }^{34}$. A pesar de no explicitarse cuáles serían esos elementos psicosociales y de qué manera se los podría caracterizar, al menos esta afirmación serviría para deducir la existencia de valores sociales en juego.

En síntesis, en la práctica clínica cotidiana el dato que definirá si un niño necesita o no de tratamiento será el de su funcionamiento diario en el contexto (escolar, familiar etc.), en relación a valores y expectativas que ese contexto social deposite sobre él y de acuerdo al cumplimiento o no de dichas expectativas por parte de ese niño. Entonces nos preguntamos: ¿son adecuadas las expectativas actualmente depositadas en los niños en relación a su educación y en relación a su conducta en el hogar?; ¿Cuáles son los valores subyacentes a dichas expectativas?

\section{EI TDAH y los valores}

Menciona Tealdi en el Diccionario latinoamericano de bioética ${ }^{35}$ que en el marco de la dimensión valorativa de la salud, pueden asociarse conceptos científicos y técnicos con valores culturales y éticos. Entre estos últimos podemos mencionar a la vida, la identidad, la integridad, la libertad, la salud y el bienestar de las personas, comunidades y distintos grupos sociales. Volviendo al caso particular de los niños con trastornos cognitivos y conductuales como el TDAH, pensar los valores mencionados en relación a este trastorno en particular nos lleva a formular otra serie de preguntas.

En el caso del valor de la vida, deberíamos preguntarnos si la plenificación de la vida de un niño con sospecha de TDAH se podría dar a punto de partida del uso de un mejorador cognitivo. ¿El mejorar la cognición para permitir tener un mejor funcionamiento escolar, implica necesariamente hacer de la vida de un niño una vida más plena? La mencionada evidencia de datos genéticos (y epigenéticos) en relación a la susceptibilidad a presentar conductas compatibles con el TDAH, y la influencia del contexto sobre la manifestación fenotípica final ponen de relieve la responsabilidad de la comunidad en la generación de contextos favorecedores del neurodesarrollo infantil y de la plenificación de la vida de los niños en actual proceso de desarr ollo.

Con respecto al valor de la identidad y en relación a los mecanismos de normalización social ¿existen en los contextos sociales donde se desarrollan los niños (escuela, familia, barrio etc.) un verdadero respeto por quien cada uno es y por lo que es en relación a su singularidad biológica y cultural?

Con respecto al valor de la libertad, ¿se toma en cuenta la opinión del niño y su familia en la toma de decisiones en cuanto a recibir o no los tratamientos con estimulantes y/o abordajes psicoeducativos? Se dice que una persona actúa con autonomía cuando tiene independencia respecto de controles externos y capacidad para obrar de acuerdo a una elección propia. La participación activa de los niños y sus respectivas familias en la toma de decisiones en cuanto al tipo de tratamiento a implementarse garantizará la puesta en práctica de este principio, sobre todo en circunstancias como las del TDAH en las cuales el diagnóstico y el tipo de intervención es- 
tán fuertemente sesgados por la presencia de valores propios de cada comunidad.

En concordancia con esta idea, el ya mencionado $3^{\circ}$ Consenso Latinoamericano sobre TDAH, reunido en la ciudad de Cartagena (2009) expresa en uno de sus apartados que la decisión de aceptar un tratamiento farmacológico debe ser responsabilidad compartida de los pacientes, el niño o adolescente y el médico. Los niños, adolescentes y adultos deben participar activamente en su tratamiento con apoyo familiar $^{36}$.

La evidencia neurocientífica pone de manifiesto que la pobreza tendría un impacto a través de ciertos factores mediadores (por ejemplo, factores de salud pre y perinatales, el ambiente del hogar y de la escuela, la disponibilidad de recursos materiales y culturales de la comunidad) sobre funciones cognitivas básicas. Algunas de estas funciones estarían involucradas en el control cognitivo temprano siendo fundamentales para todas las formas de actividad cognitiva y comportamiento social ${ }^{37}$. En relación al valor de la salud, en el caso de tener el niño un trastorno atencional, la desigualdad de acceso por razones económicas a los fármacos mejoradores cognitivos plantea un problema en relación a la equidad ya que la falta de acceso podría hacer más notorias las diferencias en el desempeño cognitivo, que por lo previamente mencionado, ya de por sí son más probables de estar presentes en niños que viven en contextos de pobreza.

Considerando el valor de la integridad y en relación a las dificultades para establecer el diagnóstico de TDAH, los médicos tienen un nivel de tolerancia a la aparición de efectos adversos farmacológicos que está dado por una relación que se define en términos de riesgo/beneficio. En el caso de los estimulantes, ¿cuál sería el nivel de tolerancia a los efectos adversos farmacológicos, en el caso de que no estuviéramos tratando un trastorno en un niño enfermo sino mejorando un rendimiento cognitivo en uno sano? Por supuesto, que el omitir un diagnóstico de trastorno cognitivo cuando éste realmente existe, puede implicar un riesgo para la integridad de la persona en la medida que ésta no reciba los tratamientos adecuados.

Entendemos a la conducta como una creación biológica global del individuo, entonces, ¿los fármacos que potencian la atención, actúan exclusivamente sobre esta habilidad o de alguna manera tienen impacto sobre la naturaleza humana en su conjunto, en una dimensión que la ciencia sólo puede dejar visualizar en forma parcial? Pensando en el bienestar de las personas y los grupos socia- les, ¿̇siempre que se trata a un niño con problemas atencionales y con hiperactividad se busca beneficiar al niño o al grupo social donde ese niño desarrolla su actividad? ¿Qué tablas de valores toman en consideración los miembros del sistema de salud y educativo al momento de enfrentarse con problemas como los que plantea el TDAH o en general los problemas del neurodesarrollo?

\section{Consideraciones finales}

El médico es en nuestra sociedad el responsable de la indicación del uso de fármacos mejoradores cognitivos. Actualmente cuenta con consensos que orientan la toma de decisiones a dicho respecto en el caso de trastornos mentales que ameriten su uso (como por ejemplo en el caso del TDAH).

El mejoramiento cognitivo farmacológico tanto cosmético (más allá de la existencia actual o no de una autorización formal por parte de los respectivos estados en cuanto a esta forma de uso de los mejoradores cognitivos) como terapéutico, implicaría desde el punto de vista del médico que prescriba estos mejoradores, facilitar el cumplimiento de ciertas expectativas sociales (permitir un buen rendimiento escolar, tener una conducta socialmente aceptable en el hogar, la escuela etc., entre otras), algunas de las cuales pueden no ser obligatoriamente compartidas por el conjunto de la sociedad.

El médico al indicar un tratamiento mejorador de la cognición adhiere implícitamente a cierto tipo de valores y expectativas sociales que buscan ser cubiertas en parte a partir del uso de los estimulantes y/o los abordajes psicoeducativos. Se hace necesario entonces, una metódica reflexión del médico acerca del sentido de aquellos valores y expectativas sociales que llevan al uso de estos recursos tecnológicos. Sin embargo, ¿cuentan los profesionales de la salud con herramientas metodológicas como para realizar esta reflexión? Sostenemos que tanto la Bioética como la Neuroética pueden ser ámbitos disciplinares válidos para orientarla.

A través de este trabajo nos hemos propuesto presentar una visión del problema del uso de los fármacos mejoradores cognitivos que parte de un análisis más amplio que aquel que se basa exclusivamente en la consideración de los potenciales efectos adversos asociados al uso de un fármaco, más allá de concordar con la importancia que esta perspectiva tiene desde el punto de vista de la integridad de las personas y sobre todo si tomamos 
en cuenta que estas personas pueden pertenecer a sectores vulnerables de la población como es el caso de los niños. En el caso particular de los médicos, la consideración por parte de los mismos de una tabla de valores amplia brindará una visión más abarcativa del universo donde se encuentra comprendida la niñez y su desarrollo, que lo que ofrecen las visiones reduccionistas a los fenómenos exclusivamente biológicos.
Esta forma distinta de caracterizar la responsabilidad médica, a punto de partida de la consideración complementaria de conceptos científicos (y hechos mensurables) y valores, debería llevar al surgimiento de un nuevo paradigma asistencial basado en clasificaciones diagnósticas que sean el resultado de una teoría más abarcadora e integradora del individuo biológico y del individuo social en relación con la vida.

Artículo elaborado teniendo como base las reflexiones presentadas durante la $1^{\circ}$ Jornada de Neuroética - Usos sociales y académicos del conocimiento acerca del cerebro, de la UNSAM (4 de noviembre de 2011).

\section{Referências}

1. Canguilhem G. El conocimiento de la vida. Barcelona: Anagrama, 1976. p. 183-200.

2. Canguilhem G. Lo normal y lo patológico. $2^{\text {a }}$ ed. México: Siglo XXI Editores; 1978. Conclusión; p. 175-88.

3. Canguilhem G. Op. cit. 1978. p. 186.

4. Morein-Zamir S, Sahakian B. Neuroethics and public engagement training needed for neuroscientists. Trends Cogn Sci. 2010;14(2):49-51.

5. Evers K. Neuroética: cuando la material se despierta. Buenos Aires: Katz; 2010. Introducción; p. 13.

6. Racine E, Illes J. Neuroethics. In: Singer P, Viens AM, editors. The Cambridge textbook of bioethics. Cambridge: Cambridge University Press; 2008. p. 495-504.

7. Glannon W. Neuroethics. Bioethics. 2006;20(I):37-52.

8. American Academy of Pediatrics. Subcommittee on Attention-Deficit/Hyperactivity Disorder. Steering Committee on Quality Improvement and Management. ADHD: clinical practice guideline for the diagnosis, evaluation and treatment of attention-deficit/hyperactivity disorder in children and adolescents. Pediatrics. [Internet]. 2011 [acesso 28 out. 2011];128(5):1-16. Disponível: http://pediatrics.aappublications.org/content/early/2011/10/14/peds.2011-2654.full.pdf

9. Barragán Pérez E, Peña Olvera F, Ortiz León S, Ruiz García M, Hernández Aguilar J, Palacios Cruz L et al. Primer consenso latinoamericano de trastorno por déficit de atención e hiperactividad. Bol Med Hosp Infant Mex. 2007;64(5):326-43.

10. Dwivedi KN, Banhatti RG. Attention déficit/hyperactivity disorder and ethnicity. Arch Dis Child. 2005;90(Suppl 1):i10-i12.

11. Asociación Estadounidense de Psiquiatría. DSM IV-TR: manual diagnóstico y estadístico de los trastornos mentales. $4^{\text {a }}$ ed rev. Barcelona: Masson; 2001.

12. American Academy of Pediatrics. Subcommittee on Attention-Deficit/Hyperactivity Disorder. Steering Committee on Quality Improvement and Management. Op. cit. p. 6.

13. Barragán Pérez E, Peña Olvera F, Ortiz León S, Ruiz García M, Hernández Aguilar J, Palacios Cruz L et al. Op. cit. p. 327.

14. Ferrater Mora J. Diccionario de filosofía. Barcelona: Ariel; 1994. Constructo; p. 673.

15. Barragán Pérez E, Peña Olvera F, Ortiz León S, Ruiz García M, Hernández Aguilar J, Palacios Cruz L et al. Op. cit. p. 328.

16. Cardo E, Bustillo M, Servera M. Valor predictivo de los criterios del DSM-IV en el diagnóstico del trastorno por déficit de atención/hiperactividad y sus diferencias culturales. Rev Neurol. 2007;44(Supl 2):s19-s22.

17. Dawson B, Trapp R. Bioestadística médica [Rebatet G., de la Garza V, trans]. $4^{\text {a }}$ ed. México: Manual Moderno; 2005. Investigación con encuestas; p. 255-74.

18. Boyce A. Neuroimaging in psychiatry: evaluating the ethical consequences for patient care. Bioethics. 2009;23(6):349-59.

19. Canguilhem G. Op. cit, 1978. Examen crítico de algunos conceptos: De lo normal, de la anomalía y de la enfermedad, de lo normal y de lo experimental. p. 91-111.

20. Le Blanc G. Canguilhem y las normas. Buenos Aires: Ediciones Nueva Visión; 2004. El hombre normal, el hombre anormal y el hombre medio. p. 54-61.

21. Thapar A, Langley K, Asherson P, Gill M. Gene-environment interplay in attention-deficit hyperactivity disorder and the importance of a developmental perspective. $\mathrm{Br} J$ Psych. 2007;190:1-3.

22. Devastar SU, Raychaudhuri S. Epigenetics: a science of heritable biological adaptation. Pediatr Res. 2007;61(5 Pt 2):1R-4R.

23. Kan K, Ploeger A, Raijmakers M, Dolan C, van der Maas H. Nonlinear epigenetic variance: review and simulations. Dev Sci. 2010;13(1):11-27. 
24. Laucht M, Skowronck M, Becker K, Schmidt M, Esser G, Schulze TG et al. Interacting effects of the dopamine transporter gene and psychosocial adversity on attention-deficit /hyperactivity disorder symptoms among 15-year olds from a high-risk community sample. Arch Gen Psychiatry. 2007;64(5):585-90.

25. Mehta MA, Goodyer IM, Sahakian BJ. Methylphenidate improves working memory and set-shifting in AD/HD: relationships to baseline memory capacity. J Child Psichol Psychiatry. 2004;45(2):293305.

26. Metha M, Owen A, Sahakian B, Mavaddat N, Pickard JD, Robbins TW. Methylphenidate enhances working memory by modulating discrete frontal and parietal lobe regions in the human brain. J Neurosci. 2000;20(6):RC65.

27. Toine P, Stephen S. Psychotropic drug use: between healing and enhancing the mind. Neuroethics. 2009;2(2):63-73.

28. Smith ME, Farah M. Are prescription stimulants "samart pills"? The epidemiology and cognitive neuroscience of prescription stimulant use by normal healthy individuals. Psychol Bull. 2011;137(5):717-41.

29. Jensen PS, Arnold LE, Swanson JM, Vitiello B, Abikoff HB, Greenhill LL et al. 3-year follow-up of the NIMH MTA study. J Am Acad Child Adolesc Psychiatry. 2007;46(8):989-1.002.

30. Parens $E$, Johnston J. Facts, values and attention-deficit-hyperactivity disorder (ADHD): an update on the controversies. Child Adolesc Psychiatry Ment Health. [Internet]. 2009 [acesso 16 set. 2010];3(1):1. Disponível: http://www.capmh.com/content/3/1/1

31. Peña Olvera F, Barragán Pérez E, Rohde LA, Durán LRP, Ramírez PZ, Flores REU et al. Algoritmo de tratamiento multimodal para escolares Latinoamericanos con trastorno por déficit de atención con hiperactividad (TDAH). Salud Ment. [Internet]. 2009 [acesso 29 out. 2011];32:S17-S29. Disponível: http://www.medigraphic.com/pdfs/salmen/sam-2009/sams091c.pdf

32. Grañana N, Richaudeau A, Robles Gorriti C, O’Flaherty M, Scotti ME, Sixto L et al. Evaluación de déficit de atención con hiperactividad: la escala SNAP IV adaptada a la Argentina. Rev Panam Salud Publica. 2011;29(5):344-9.

33. Peña Olvera F, Barragán Pérez E, A. Rohde L, Durán LRP, Ramírez PZ, Flores REU et al. Op cit. p. 24.

34. Peña Olvera F, Palacio Ortiz JD, Barragán Pérez E. Declaración de Cartagena para el trastorno por déficit de atención con hiperactividad (TDAH): rompiendo el estigma. Rev Cienc Salud. [Internet]. 2010 [acesso 29 out. 2011];8(1):93-8. Disponível: http://redalyc.uaemex.mx/redalyc/ pdf/562/56216305009.pdf

35. Tealdi JC. Diccionario latinoamericano de bioética. [Internet]. Bogotá: Unesco/Universidad Nacional de Colombia; 2008 [acesso $1^{\circ}$ nov. 2011]. Salud y enfermedad; p. 560

36. Peña Olvera F, Palacio Ortiz JD, Barragán Pérez E. Op. cit. p. 96.

37. Lipina S, Hermida M, Segretín MS, Prats L, Frachia C, Colombo JA. Investigación en pobreza infantil desde perspectivas neurocognitivas. In: Lipina S, Sigman M, editores. La pizarra de Babel: puentes entre neurociencia, psicología y educación. Buenos Aires: Libros del Zorzal; 2011. p. 243-63.

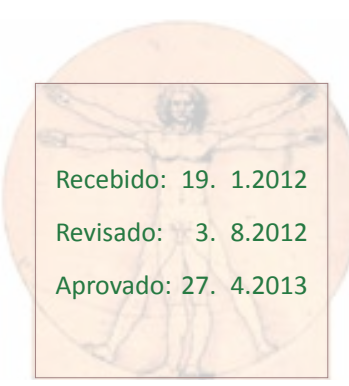

